\title{
Composition, abundance and aspects of temporal variation in the distribution of Anopheles species in an area of Eastern Amazonia
}

\author{
Ledayane Mayana Costa Barbosa ${ }^{[1]}$, Raimundo Nonato Picanço Souto ${ }^{[1]}$, \\ Ricardo Marcelo dos Anjos Ferreira ${ }^{[2]}$ and Vera Margarete Scarpassa ${ }^{[3]}$
}

[1]. Laboratório de Arthropoda, Departamento de Ciências Biológicas e da Saúde, Universidade Federal do Amapá, Macapá, AP. [2]. Plataforma Paulo Freire, Universidade Federal do Amapá, Macapá, AP. [3]. Laboratório de Genética de Populações e Evolução de Mosquitos Vetores de Malária e Dengue, Coordenação de Biodiversidade, Instituto Nacional de Pesquisas da Amazônia, Manaus, AM.

\begin{abstract}
Introduction: The diverse and complex environmental conditions of the Amazon Basin favor the breeding and development of Anopheles species. This study aimed to describe the composition, abundance and temporal frequency of Anopheles species and to correlate these factors with precipitation, temperature and relative humidity. Methods: The study was conducted in the District of Coração, State of Amapá, Brazil. Samples were collected monthly during three consecutive nights, from 6:00 PM to 10:00 PM, from December 2010 to November 2011. In addition, four 12-hour collections (i.e., 6:00 PM to 6:00 AM) were performed during this period. Results: A total of 1,230 Anopheles specimens were collected. In the monthly collections, Anopheles darlingi was the predominant species, followed by An. braziliensis and An. albitarsis s.l., whereas An. darlingi, An. peryassui and An. braziliensis were the most frequent species collected in the 12-hour collections. The greatest number of anophelines was collected in September (the dry season). The highest frequency of anophelines was observed for An. darlingi during September, when there were the least rainfalls of the year, along with lower relative humidity and higher temperatures. There was little variation in the abundance of this species in other months, with the exception of slight increases in February, July and August. Conclusions: The major malaria vectors, An. darlingi and An. albitarsis s.l. (likely An. marajoara), were the most abundant species collected in the study area. Consequently, prevention and control measures should be taken to prevent malaria outbreaks in the District of Coração.
\end{abstract}

Keywords: Diversity of species. Anopheles darlingi. Malaria vector. Brazilian Amazon.

\section{INTRODUCTION}

Entomological studies on the diversity, density, behavioral patterns (particularly anthropophily, zoophily and bite peak) and temporal variations of Anopheles species have supported the identification and monitoring of malaria vectors ${ }^{1,2}$. The capacity of a vector species to transmit malaria involves a combination of factors, including abundance, anthropophily, susceptibility to infection by the malaria parasite, infection rates and female longevity ${ }^{3}$. Anthropophily, susceptibility and longevity are the major epidemiological factors in malaria transmission, whereas the abundance of anopheline species is the most common entomological measurement used to determine the correlation between vectors and malaria incidence ${ }^{4}$.

Address to: $\mathrm{M}^{\mathrm{e}}$. Ledayane Mayana Costa Barbosa. Lab. Arthropoda/Dept ${ }^{\mathrm{o}}$ de Ciências Biológicas e da Saúde/UNIFAP. Rodovia Juscelino Kubitschek, KM-02, Jardim Marco Zero, 68903-419, Macapá, AP, Brasil.

Phone: 55 96 9124-1304

e-mail: barbosalmc@unifap.br; rnpsouto@unifap.br

Received 1 December 2013

Accepted 16 June 2014
In recent years, malaria transmission has decreased in the Brazilian Amazon region, likely because of improved control programs. All states within this region experienced reduced numbers of malaria cases ${ }^{5}$. However, although there was an overall reduction in malaria cases in the State of Amapá, an increase in the number of cases was recorded in some municipalities, such as Macapá, Mazagão, Calçoene and Tartarugalzinho ${ }^{5}$. In addition, the number of malaria cases caused by Plasmodium falciparum has increased ${ }^{5}$. This increase is a cause for concern because the main malaria vector, Anopheles darlingi, is widely distributed in the state of Amapá ${ }^{1,6-9}$ and has been captured at high densities in some localities ${ }^{1,4,10,11}$. This framework justifies further studies in this state to improve knowledge of the diversity and behavior of this species, thus facilitating monitoring and vector control efforts. This study aimed to describe the composition, abundance and temporal frequency of Anopheles species and to analyze the possible influence of climatic factors on their distribution in a peri-urban area with recent urban developments in the northern Brazilian Amazon region. The data presented here are part of a broader study in which the parameters related to the transmission dynamics (intradomicile and peridomicile, anthropophily, zoophily, parity rate and natural infection rate) of Anopheles species were analyzed. 


\section{METHODS}

The study area was the District of Coração, located at km 13 Duca Serra Road in the outskirts of Macapá City, State of Amapá, Brazil $\left(0^{\circ} 01{ }^{\prime} 22^{\prime \prime} \mathrm{N}\right.$; 51 $1^{\circ} 10^{\prime} 26^{\prime \prime} \mathrm{W}$; Figure 1). The District of Coração was chosen because, according to the records of the Health Surveillance Secretariat of the State of Amapá, it is an area of high malaria transmission, and to date, no studies have investigated the diversity and behavior of Anopheles species in this area. This district has 1,731 inhabitants. The homes are brick-walled, with most doors and windows protected by screens. The District of Coração belongs to the morphoclimatic Amazon Savanna environment domain, which includes savanna, fields, and islands of non-flooded forest and gallery forest; the majority of its landscape is covered with buriti

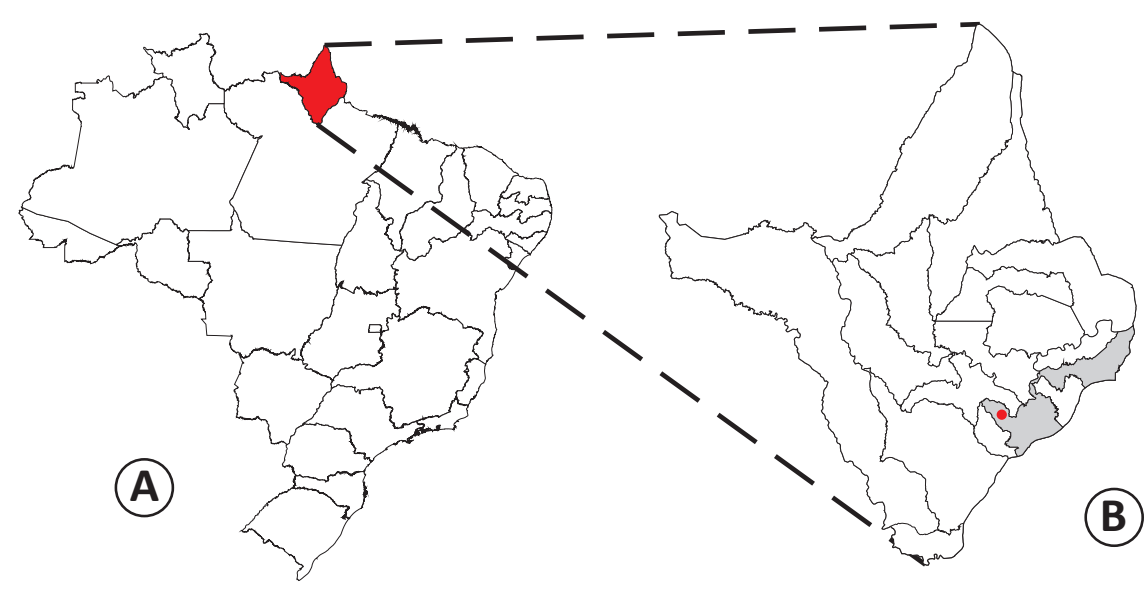

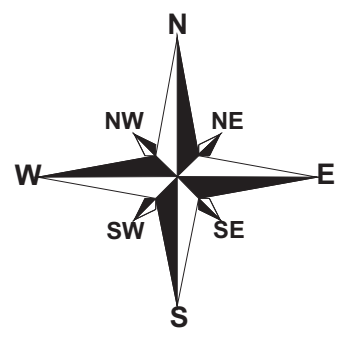

- Collection points $10050 \quad 0 \quad 100 \mathrm{~m}$

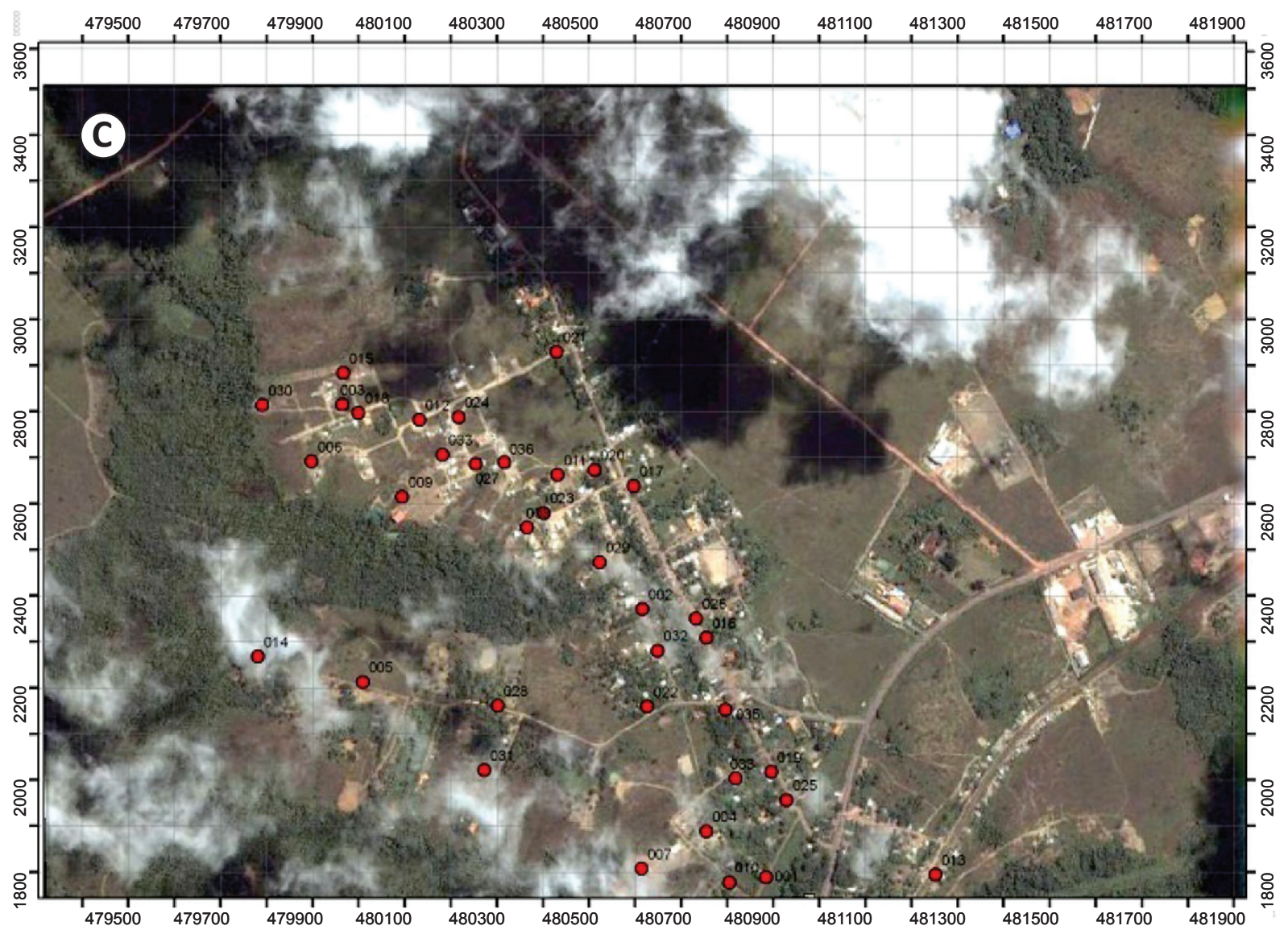

FIGURE 1 - Location of the District of Coração within Brazil. A: In detail, in the State of Amapá. B: Location of the study area in the State of Amapá. C: A satellite image of the studied areas. The collection points are highlighted. 
palm trees (Mauritia flexuosa $)^{12}$. The surrounding wetlands are under the influence of precipitation and the Matapi River. Drainages in the gallery forest connect with the river, which maintains a minimum water level during the dry periods. The climate conditions of the region are typically hot and humid (mean humidity $\sim 85 \%$ ), with temperatures ranging from 22 to $32^{\circ} \mathrm{C}$. The rainy and dry seasons extend from January to July and from August to December, respectively. Climatic data of the monthly accumulated precipitation $(\mathrm{mm})$, mean relative humidity $(\%)$ and temperature $\left({ }^{\circ} \mathrm{C}\right)$ were obtained from the National Institute for Space Research/National System for Environmental Data (INPE/SINDA - Instituto Nacional de Pesquisas Espaciais/Sistema Nacional de Dados Ambientais).

From December 2010 to November 2011, adult specimens were collected for three consecutive nights each month. Collections were performed at a total of 36 collection sites. The capture duration was four hours between 6:00PM and 10:00PM. The 36 sites were randomly distributed within the urban area of the district, with an average distance of 1,500 meters between each site. Additionally, four uninterrupted 12hour collections were performed from 6:00 PM to 6:00 AM, two in the rainy season (February and May, 2009) and two in the dry season (August and November, 2009). There were always two collectors for each collection. The mosquitoes were spotted with the aid of a flashlight and captured with a manual-type capturer (Castro) when they attempted to land on the collectors' skin $^{13}$. The entomological investigation and collection methodology adopted in the present study were reviewed and approved by the Research Ethics Committee of the National Institute for Research in the Amazon (INPA Instituto Nacional de Pesquisas da Amazônia, Manaus, Brazil) under process number 036/2010.

After the captures, the mosquitoes were transferred into plastic cups, properly labeled and then transported alive inside tightly closed isothermal boxes ${ }^{14}$ to the Arthropoda Laboratory of the Federal University of Amapá (Macapá, Brazil). The Anopheles spp. species collected were identified using morphological keys that are specific to the group ${ }^{15-17}$, and the genus and subgenus abbreviations used were in accordance with Reinert ${ }^{18}$. Because the morphological differences between members of the An. albitarsis, An. nuneztovari and An. triannulatus complexes were not defined in this study, they were referred to as sensu lato. However, the species collected belonging to the An. albitarsis complex were most likely An. marajoara, as previous studies confirmed its presence in this region based on molecular markers ${ }^{19}$. Similarly, Anopheles mediopunctatus and An. forattinii, two cryptic species that cannot be identified by female morphological characters, were identified and separated by a slash in the manuscript.

The frequencies in the figures are expressed as absolute and relative frequencies. The specimens collected during the monthly periods and the four 12-hour periods were analyzed for richness and abundance parameters. For the statistical analyses, the Kruskal-Wallis test and Spearman's correlation analysis were performed using BioEstat software version 5. $0^{20}$. A significance threshold of $\alpha=0.05$ was used for all tests.
The specimens obtained in the monthly collections were analyzed for temporal variation. In this analysis, the variables tested were species abundance and abiotic factors, such as precipitation, temperature and relative humidity.

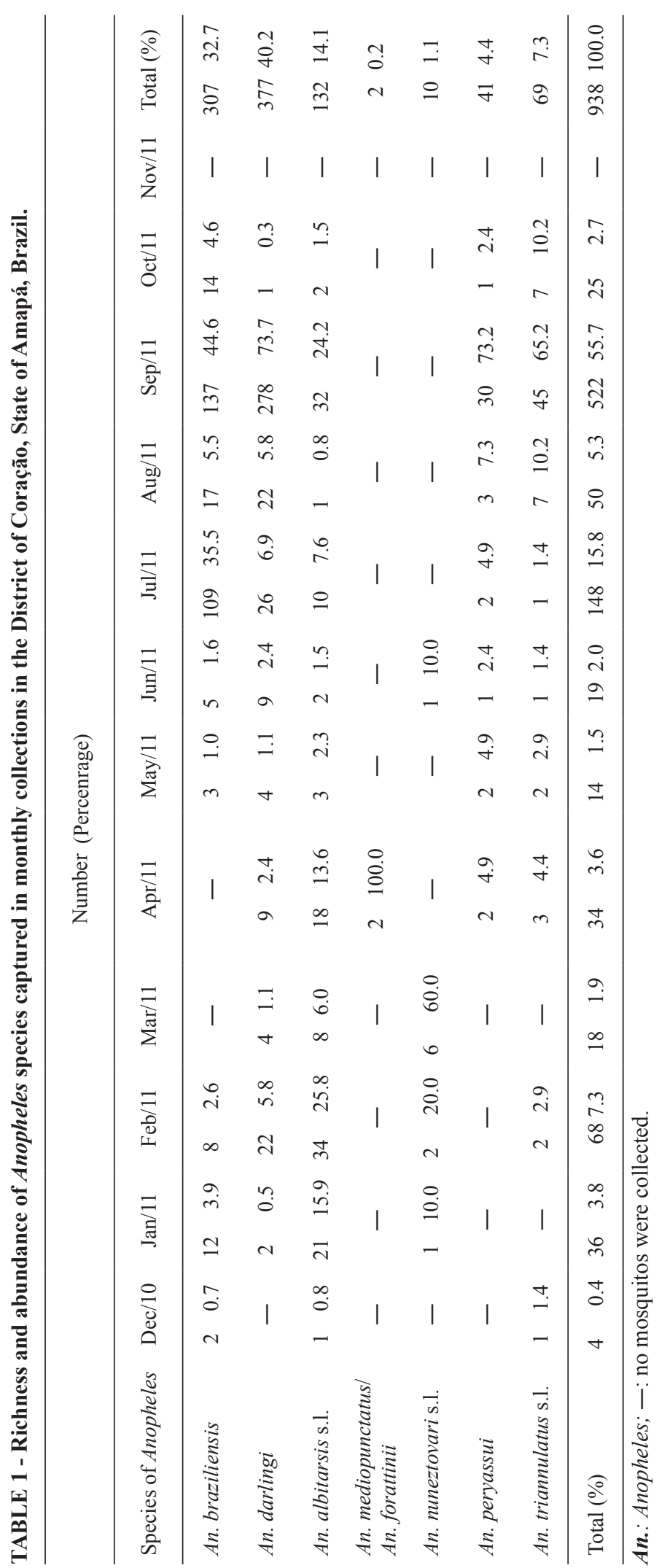




\section{RESULTS}

A total of 1,230 anophelines were collected and identified as eight species and two subgenera, including five Nyssorhynchus and three Anopheles species: Anopheles (Nyssorhynchus) braziliensis, Anopheles (Nyssorhynchus) darlingi, Anopheles (Nyssorhynchus) albitarsis s.1., Anopheles (Nyssorhynchus) nuneztovari s.l., Anopheles (Nyssorhynchus) triannulatus s.1., Anopheles (Anopheles) intermedius, Anopheles (Anopheles) mediopunctatus/Anopheles (Anopheles) forattinii and Anopheles (Anopheles) peryassui.

Anopheles darlingi (47.1\%) was the predominant species, followed by An. braziliensis (27.1\%) and An. albitarsis s.1. $(12.2 \%)$. The frequencies of the remaining species (i.e., An. nuneztovari s.1., An. triannulatus s.l., An. intermedius, An. mediopunctatus/An. forattinii and An. peryassui) were $<10 \%$.

In the monthly (four-hour) collections, 938 specimens were captured and distributed into seven species (Table 1). The largest number of anophelines was sampled in September (dry season), followed by July (late rainy season). There was a sharp decrease in the anopheline fauna during October, and no anophelines were collected in November.

The species with the highest density (40.2\%) during the study was Anopheles darlingi, whose greatest frequency was observed in September (73.7\%), followed by An. braziliensis (32.7\%). The latter species was the most abundant in July (35.5\%), January (3.9\%) and October (4.6\%). Anopheles albitarsis s.1. was the third most frequent species (14.1\%) observed during the collections, with the greatest frequencies in February (25.8\%) and September (24.2\%). Anopheles peryassui and An. triannulatus s.l. were not abundant during the study, but they showed population growth in September $(73.2 \%$ and $65.2 \%$, respectively). Anopheles mediopunctatus/An. forattinii and An. nuneztovari s.l. had the lowest frequencies (Table 1). The Kruskal-Wallis test revealed non-significant differences in the frequencies of the species between the sampling months $(\mathrm{H}=17,700 ; \mathrm{p}=0.088)$.

In the four 12-hour collections, a total of 292 specimens were collected and grouped into seven species (Table 2). The highest abundances were observed in May (37\%) and August (47.3\%), and the lowest abundances were observed in February (10.9\%) and November (4.8\%). Anopheles darlingi was the most (69.2\%) frequent species, followed by An. peryassui (11.6\%). Although An. albitarsis s.l. was observed at a low (6.2\%) frequency, it was present in all four sample periods, as was An. darlingi. Anopheles intermedius and An. nuneztovari s.l. were each only captured during a single period (November and February, respectively) and were found at low $(0.3 \%)$ frequencies. The Kruskal-Wallis test showed a statistically non-significant difference in the frequencies of Anopheles species among the four sampling periods $(H=2,386 ; p=0.496)$.

During the study period, the heaviest rainfalls occurred in March, April, May and July. Higher temperatures extended from August to November, and the periods of highest relative humidity occurred from January to May. The largest number of specimens was collected in September, during the dry season, when there were the least rainfalls of the year, along with lower relative humidity and higher temperatures. There was no significant correlation between the number of anophelines collected and the tested climatic variables, although the number of anophelines increased with a decrease in precipitation and with an increase in temperature.

Regarding the abundance of Anopheles species in this study, the greatest frequency was observed for An. darlingi in September (Figure 2). In the other months, there was little variation in the abundance of this species, with the exception of slight increases in February, July and August, and there was

TABLE 2 - Richness and abundance of Anopheles species distributed between four 12-hour collection periods in the District of Coração, State of Amapá, Brazil.

\begin{tabular}{|c|c|c|c|c|c|c|c|c|c|c|}
\hline \multirow{2}{*}{$\frac{\text { Species of Anopheles }}{\text { Anopheles braziliensis }}$} & \multicolumn{10}{|c|}{ Number (Percentage) } \\
\hline & - & - & 1 & 3.7 & 20 & 74.1 & 6 & 22.2 & 27 & 9.3 \\
\hline Anopheles darlingi & 23 & 11.4 & 101 & 50.0 & 72 & 35.6 & 6 & 3.0 & 202 & 69.2 \\
\hline Anopheles intermedius & - & - & - & - & - & - & 1 & 100.0 & 1 & 0.3 \\
\hline Anopheles nuneztovari s.l. & 1 & 100.0 & - & - & - & - & - & - & 1 & 0.3 \\
\hline Anopheles peryassui & - & - & - & - & 34 & 100.0 & - & - & 34 & 11.6 \\
\hline Anopheles triannulatus s.l. & 1 & 11.1 & 2 & 22.2 & 6 & 66.7 & - & - & 9 & 3.1 \\
\hline Total (\%) & 32 & 10.9 & 108 & 37.0 & 138 & 47.3 & 14 & 4.8 & 292 & 100.0 \\
\hline
\end{tabular}

-: no mosquitos were collected 

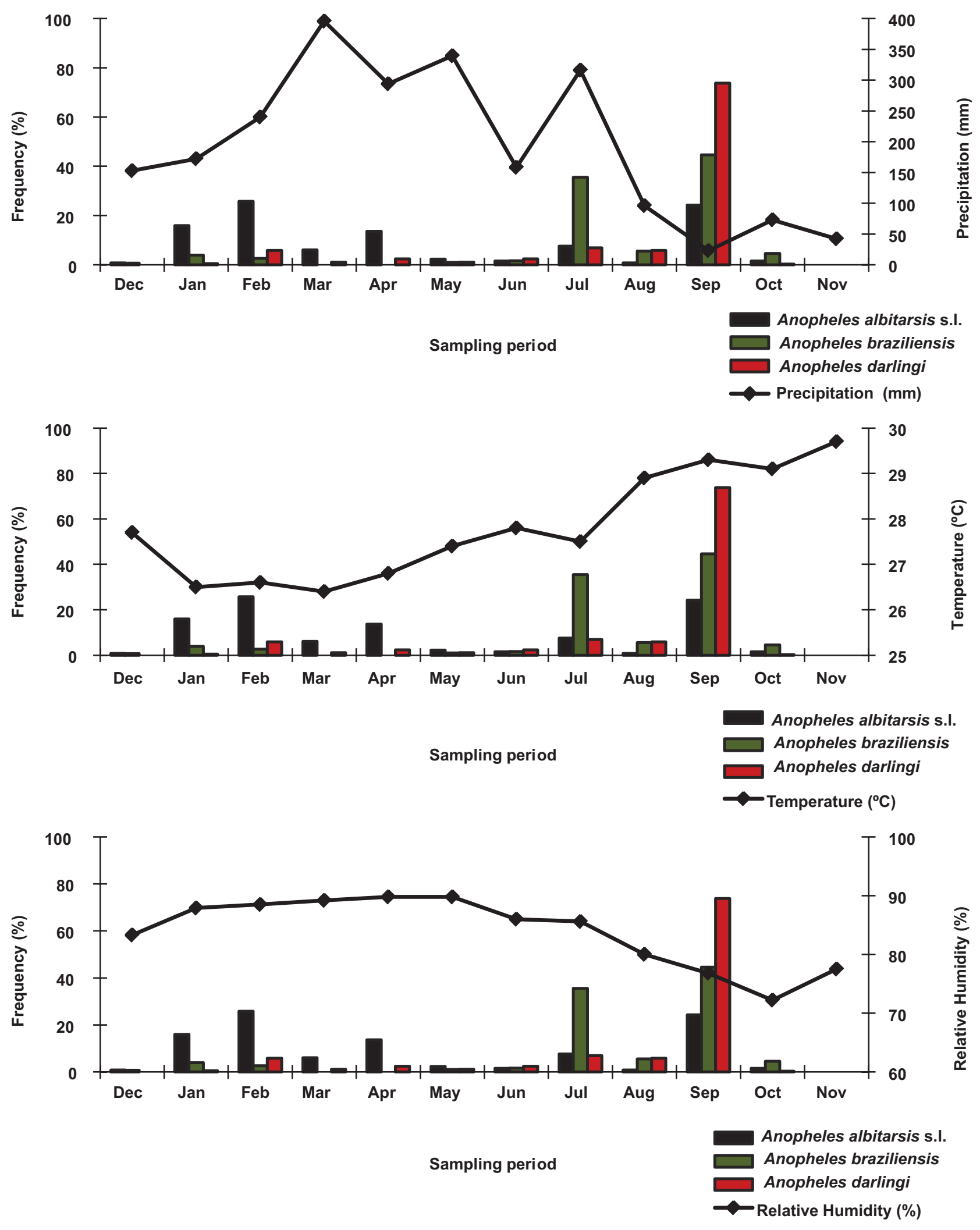

FIGURE 2 - Frequency of Anopheles albitarsis s.l., Anopheles braziliensis and Anopheles darlingi in relation to the climatic variables, based on the monthly collections performed in the District of Coração, State of Amapá, within Brazil. 
a unimodal temporal distribution. As for An. braziliensis, there was a pronounced increase in its density in September and July, with a bimodal pattern (temporal distribution) throughout the year. For An. albitarsis s.1., higher frequencies were observed in January, February, April and September, with a multimodal temporal distribution. No specimens were captured in November.

Correlation tests were performed for the three most abundant species. There were no statistically significant correlations between rainfall and An. darlingi ( $\mathrm{rs}=0.109 ; \mathrm{p}=0.735)$, An. albitarsis s.l. ( $\mathrm{rs}=0.322 ; \mathrm{p}=0.306)$ or An. braziliensis ( $\mathrm{rs}=-0.345 ; \mathrm{p}=0.271)$. In addition, there were no significant correlations regarding temperature.

\section{DISCUSSION}

The three predominant species in the study area during the monthly collections were An. darlingi, An. braziliensis and An. albitarsis s.l., whereas the most frequent species during the 12-hour collections were An. darlingi, An. peryassui and An. braziliensis. Among these species, two (An. darlingi and An. albitarsis s.1.) have been implicated as major malaria vectors in the state of Amapá6, ${ }^{6,11,11}$. A similar result was obtained by another study ${ }^{21}$ along the Matapí River, an area close to the present study area, where the most abundant species were An. darlingi and An. marajoara.

Anopheles darlingi is a major malaria vector in the Americas $^{22}$, where it transmits malaria both within and near homes ${ }^{23-27}$. Earlier studies implicated this species as being the main malaria vector in Brazil ${ }^{28-30}$. These findings were later corroborated by other reports in the Brazilian Amazon region $^{1,24-26,31,32}$, as this species is highly anthropophilic and susceptible to infection by Plasmodium spp. ${ }^{29}$. Subsequently, An. marajoara was implicated as an important regional and/or local malaria vector in areas of Amapá ${ }^{719}$, including the areas close to the present study ${ }^{4,11,21}$.

Based on these results, we believe that the District of Coração deserves constant monitoring of Anopheles species and epidemiological surveillance, as there is a constant influx of people from malarious areas in the Brazilian Amazon to this district (District of Coração public health care unit: Personal Communication, 2012). These factors may favor the reintroduction and local spread of Plasmodium spp., thereby triggering malaria outbreaks. Although the mosquito species that are thought to be malaria vectors were the most abundant in the district, the malaria incidence was not high during this study (District of Coração public health care unit, 2012).

In this study, An. mediopunctatus/An. forattinii specimens were collected in more distant residences, in the surrounding environment where there is little disturbance by humans and near gallery forest vegetation where the location of water bodies favors the formation of natural breeding sites. We also observed the presence of fish ponds during this study. Anopheles intermedius and An. peryassui are predominantly zoophilic, preferring the wild or rural environment, and thus far, they have not been implicated in the transmission of malaria in Brazil. However, these species were reported to be naturally infected with Plasmodium spp. in the Brazilian Amazon ${ }^{2,7}$ and may be involved in malaria transmission when present in high densities.

Anopheles nuneztovari s.l. was found to be infected with Plasmodium falciparum, $P$. vivax (two variants) and $P$. malariae at sites close to the present study area, together with An. darlingi and An. marajoara, and it may become an important malaria vector when present at high densities ${ }^{11}$. Anopheles braziliensis was also observed at a high density here; however, its involvement in malaria transmission requires further research.

During the monthly collections, the highest density of anophelines was obtained in September (dry season). Thus, An. darlingi had the highest density in September, soon after the rainy season ended, which has been observed in previous studies. Subsequently, a drastic decrease of anophelines was observed in October. We believe that this result was likely because of the intense fires in areas of the District of Coração, which often occur in October because it is the hottest and driest month of the year. In this study, An. darlingi and An. albitarsis s.l. were the only species captured in all four collection periods (12-hour collections). This result clearly suggests that vector control measures should be performed in the District of Coração to prevent malaria outbreaks and epidemics.

Anopheles darlingi had a unimodal temporal distribution, with the highest density in the dry season (September), whereas An. albitarsis s.l. showed two slight peaks (rainy and dry seasons). A similar pattern was observed for these species in the State of Amapá (Brazil) and in Venezuela ${ }^{9,33}$. In Venezuela ${ }^{34}$, the highest density of An. darlingi was observed when the precipitation level was the lowest, a situation that was also observed in this study and has been reported in other parts of the Brazilian Amazon ${ }^{1,9,11,35}$. The increased mosquito density was related to the previous rainy period, which maintained a water level that was sufficient for breeding sites; therefore, precipitation is a controlling factor in the density of Anopheles ${ }^{9}$. In the humid areas surrounding the District of Coração, there are sources capable of providing a water level that is sufficient to maintain breeding sites even during less rainy periods.

In this study, there was little variation in temperature and humidity throughout the year, and these factors did not significantly affect the Anopheles density. Hence, there was no correlation between these variables and the mosquito density. The temperature and humidity varied within the optimal ranges for the vital activities of mosquitoes ${ }^{17}$, exerting their influence only at higher intensity variations ${ }^{36}$. Despite the absence of an established correlation, there is clearly an influence of precipitation on the density of Anopheles because it ensures the formation and maintenance of water supplies for breeding sites $^{9,21}$. Previous studies conducted in Venezuela ${ }^{33,37}$ have also failed to find a significant correlation between these variables and the abundance of anophelines.

In recent years, the Program for Malaria Control in Brazil has focused its strategies on the early diagnosis and immediate treatment of the infected population, as well as the implementation of vector control measures. Here, our findings 
revealed that the major vectors were the most abundant species in the District of Coração; consequently, this area is at high risk of a malaria outbreak. Therefore, constant prevention measures, particularly in the late rainy season, should be taken to prevent such outbreaks.

\section{ACKNOWLEDGMENTS}

The authors thank the Federal University of Amapá (UNIFAP/Amapá) and the National Institute for Amazônia Research (INPA/Amazonas).

\section{CONFLICT OF INTEREST}

The authors declare that there is no conflict of interest.

\section{FINANCIAL SUPPORT}

The authors acknowledge support from Conselho Nacional de Desenvolvimento Científico e Tecnológico (CNPq); Fundação de Amparo à Pesquisa do Estado do Amazonas (FAPEAM); Pró-Equipamentos-CAPES; and Projeto Grandes Vultos do MCTI/INPA, Brazil. LMCB received a fellowship from CAPES.

\section{REFERENCES}

1. Tadei WP, Dutary-Thatcher B, Santos JM, Scarpassa VM, Rodrigues IB, Rafael MS. Ecologic observations on anopheline vectors of malaria in the Brazilian Amazon. Am J Trop Med Hyg 1998; 59:325-335.

2. Tadei WP, Dutary-Thatcher B. Malaria vectors in the Brazilian Amazon: Anopheles of the subgenus Nyssorhynchus. Rev Inst Med Trop São Paulo 2000; 42:87-94.

3. Lounibos LP, Conn JE. Malaria vector heterogeneity in South America. Am Entomol 2000; 46:238-249.

4. Zimmerman RH, Galardo AKR, Lounibos LP, Arruda M, Wirtz RA. Bloodmeal hosts of Anopheles species (Diptera: Culicidae) in a malaria endemic area of the Brazilian Amazon. J Med Entomol 2006; 43:947-956.

5. Ministério da Saúde. Secretaria de Vigilância em Saúde. Situação epidemiológica da malária no Brasil, 2000 a 2011. Boletim Epidemiológico 2013; 44:1-16.

6. Segura MNO. Estudo do Anopheles (Nys.) darlingi Root, 1926 e Anopheles (Nys.) albitarsis Arribalzága, 1878 (Diptera: Culicidae) como vetores de malária numa mesma área de transmissão, e caracterização de espécies do Complexo albitarsis. [Dissertation]. [Belém (PA)]: Universidade Federal do Pará; 1998.

7. Póvoa MM, Wirtz RA, Lacerda RNL, Miles MA, Warhurst D. Malaria vectors in the municipality of Serra do Navio, state of Amapa, Amazon region, Brazil. Mem Inst Oswaldo Cruz 2001; 96:179-184.

8. Voorham J. Intra-population plasticity of Anopheles darlingi's (Diptera: Culicidae) biting activity patterns in the state of Amapa, Brazil. Rev Saude Publica 2002; 36:75-80.

9. Barbosa LMC, Souto RNP. Aspectos ecológicos de Anopheles (Nyssorhyncus) darlingi Root 1926 e Anopheles (Nyssorhyncus) marajoara Galvão e Damasceno 1942 (Diptera: Culicidae) nos bairros Marabaixo I e Zerão, Macapá, Amapá, Brasil. Biota Amazônia 2011; 1:19-25.

10. Couto AA, Calvosa VS, Lacerda R, Castro F, Rosa ES, Nascimento JM. Control of malaria transmission in gold-mining area in Amapá state with the participation of private. Cad Saude Publica 2001; 17:897-907.
11. Galardo AKR, Arruda M, D'Almeida Couto AAR, Wirtz RA, Lounibos LP, Zimmerman RH. Malaria vector incrimination in three rural riverine villages in the Brazilian Amazon. Am J Trop Med Hyg 2007; 76:461-469.

12. Superintendência de Desenvolvimento da Amazônia. Projeto de hidrologia e climatologia da Amazônia. Atlas Climatológico da Amazônia brasileira. Belém: SUDAM; 1984.

13. Forattini OP, Kakitani I, Santos RLC, Ueno HM, Kobayashi KM. Role of Anopheles (Kerteszia) bellator as malaria vector in South-Eastern Brazil. Mem Inst Oswaldo Cruz 1999; 94:715-723.

14. Forattini OP. Entomologia medica. Parte Geral, Diptera, Anophelini. Vol. 1. São Paulo: Faculdade de Higiene e Saúde Pública, Universidade de São Paulo; 1962.

15. Faran ME, Linthicum KJ. A handbook of the Amazonian species of Anopheles (Nyssorhynchus) (Diptera, Culicidae). Mosq Syst 1983; 113:1-81.

16. Consoli RAGB, Lourenço-de-Oliveira R. Principais Mosquitos de Importância Sanitária no Brasil. $1^{\text {rd }}$ ed. Rio de Janeiro: Fundação Oswaldo Cruz; 1994.

17. Forattini OP. Culicidologia Médica. Vol 2. São Paulo: Editora da Universidade de São Paulo; 2002.

18. Reinert JF. Revised list of abbreviations for genera and subgenera of Culicidae (Diptera) and notes on generic and subgeneric changes. J Am Mosq Control Assoc 2001; 17:51-55.

19. Conn JE, Wilkerson RC, Segura MNO, Souza RTL, Schlichtinh CD, Wirtz RA, et al. Emergence of a new Neotropical malaria vector facilitated by human migration and changes in land use. Am J Trop Med Hyg 2002; 66:18-22.

20. Ayres M, Ayres MJR, Ayres DL, Santos AAS. BioEstat: Aplicações estatísticas nas áreas das ciências biológicas e médicas. Versão 5.0. Belém, Pará: Sociedade Civil Mamirauá, MCT-CNPq; 2007.

21. Galardo AKR, Zimmerman RH, Lounibos LP, Young LJ, Galardo CD, Arruda M, et al. Seasonal abundance of anopheline mosquitoes and their association with rainfall and malaria along the Matapi River, Amapá, Brazil. Med Vet Entomol 2009; 23:335-349.

22. Hiwat H, Bretas G. Ecology of Anopheles darlingi Root with respect to vector importance: a review. Parasites and Vectors 2011; 4:177.

23. Gutiérrez LA, González JJ, Gómez GF, Castro MI, Rosero DA, Luckhart S, et al. Species composition and natural infectivity of anthropophilic Anopheles (Diptera: Culicidae) in the states of Códoba and Antioquia, Nortwestern Colombia. Mem Inst Oswaldo Cruz 2009; 104: 1117-1124.

24. Tadei WP, Santos JMM, Costa WLS, Scarpassa VM. Biologia de anofelinos amazônicos XII. Ocorrência de espécies de Anopheles, dinâmica de transmissão e controle da malária na zona urbana de Ariquemes (Rondônia). Rev Inst Med Trop São Paulo 1988; 30:221-251.

25. Lourenço-de-Oliveira R, Guimarães AG, Arlé M, Silva TF, Castro MG, Motta MA, et al. Anopheline species, some of their habits and relation to malaria in endemic areas of Rondônia state, Amazon region of Brazil. Mem Inst Oswaldo Cruz 1989; 84:501-514.

26. Gil LHS, Alves FP, Zieler H, Salcedo JMV, Durlacher RR, Cunha RPA, et al. Seasonal Malaria Transmission and Variation of Anopheline Density in Two Distinct Endemic Areas in Brazilian Amazônia. J Med Entomol 2003; 40:636-641.

27. Martins-Campos KM, Pinheiro WD, Vítor-Silva S, Siqueira AM, Melo GC, Rodrigues C, et al. Integrated vector management targeting Anopheles darling populations decreases malaria incidence in an unstable transmission area, in the rural Brazilian Amazon. Malaria J 2012; 11:351.

28. Deane LM, Causey OR, Deane MP. Notes on the biology of Anopheles and northeastern regions of Brazil's Amazon. Rev Serv Esp Saude Publica $1948 ; 1: 827-965$.

29. Deane LM. Malaria vectors in Brazil. Mem Inst Oswaldo Cruz 1986; 81(supl II):5-14

30. Rachou RG. Anophelines in Brazil. Behavior of vector species of malaria. Rev Bras Malar D Trop 1958; 10:145-181.

31. Tadei WP, Santos JMM, Scarpassa VM, Rodrigues IB. Incidence, distribution and ecological aspects of Anopheles species (Diptera: Culicidae) in natural areas and environmental impact in the Brazilian 
Amazon. In: Ferreira EJG, Santos GM, Leão ELM, Oliveira LA, editors. Bases científicas para estratégias de preservação e desenvolvimento da Amazônia. $1^{\text {st }}$ Ed. Manaus: Instituto Nacional de Pesquisas da Amazônia; 1993; p. 167-196.

32. Póvoa MM, Conn JE, Schlichting CD, Amaral JCOF, Segura MNO, Silva ANM, et al. Malaria Vectors, Epidemiology, and the Re-Emergence of Anopheles darlingi in Belém, Pará, Brazil. J Med Entomol 2003; 40:379-386.

33. Moreno JE, Rubio-Palis Y, Paez E, Perez E, Sanchez V. Abundance, biting behaviour and parous rate of anopheline mosquito species in relation to malaria incidence in gold-mining areas of southern Venezuela. Med Vet Entomol 2007; 21:339-349.

34. Moreno JE, Rubio-Palis Y, Pérez E, Sánchez V, Páez E. Evaluación de tres métodos de captura de anofelinos en un área endémica de malaria del estado Bolívar, Venezuela. Entomotropica 2002; 17:157-165.
35. Moutinho PR. Dinâmica e estrutura populacional do Anopheles darlingi em um assentamento rural na floresta amazônica, Acre, Brasil [Dissertation]. [Botucatu (SP)]: Instituto de Biociências de Botucatu, Universidade Estadual Paulista; 2010.

36. Tadei WP, Mascarenhas BM, Podestá MG. Biology of Amazonian anopheline. VIII. Knowledge about the distribution of Anopheles species in the region of Tucurui-Maraba (Para). Acta Amaz 1983; 13:103-140.

37. Magris M, Rubio-Palis Y, Menares C, Villegas L. Vector bionomics and malaria transmission in the Upper Orinoco River, Southern Venezuela. Mem Inst Oswaldo Cruz 2007; 102:303-311. 